\title{
Comparison of Two Cough-Augmentation Techniques Delivered by a Home Ventilator in Subjects With Neuromuscular Disease
}

\author{
Lorena Del Amo Castrillo, Matthieu Lacombe, Aurélien Boré, Isabelle Vaugier, Line Falaize, \\ David Orlikowski, Hélène Prigent, and Frédéric Lofaso
}

\begin{abstract}
BACKGROUND: Breath-stacking, which consists of taking 2 or more consecutive ventilator insufflations without exhaling, is a noninvasive and inexpensive cough-assistance technique for patients with neuromuscular disease. Volumetric cough mode (VCM) is a recently introduced ventilator mode consisting of a programmable intermittent deep breath equal to a set percentage of the baseline tidal volume. Here, our objective was to compare VCM to breath-stacking during volumecontrol continuous mandatory ventilation in subjects on long-term noninvasive mechanical ventilation at home. METHODS: We included 20 subjects with neuromuscular disease causing severe respiratory muscle dysfunction with a cough peak flow $(\mathrm{CPF})<270 \mathrm{~L} / \mathrm{min}$ or maximum expiratory pressure $<45 \mathrm{~cm} \mathrm{H}_{2} \mathrm{O}$. Each subject tested breath-stacking and VCM in random order. RESULTS: CPF increased with both techniques but was higher with VCM than with breath-stacking in 16 subjects. In 17 subjects, CPF was highest with the technique that produced the greatest inspiratory capacity. CONCLUSION: Our results indicate that both breath-stacking and VCM are useful cough-augmentation techniques. Displaying insufflated volumes on the ventilator screen is a simple and accessible method for selecting the most efficient cough-augmentation technique delivered by a home ventilator. Key words: cough; mechanical insufflation; neuromuscular diseases; intermittent positive-pressure breathing; respiratory failure. [Respir Care 2019;64(3):255-261. () 2019 Daedalus Enterprises]
\end{abstract}

\section{Introduction}

Impaired cough resulting in an inability to clear the airways of secretions is among the factors causing acute respiratory failure in subjects with neuromuscular disease. ${ }^{1}$ Cough peak flow (CPF) is widely considered to predict cough efficiency ${ }^{2,3}$ and successful weaning from invasive mechan-

\footnotetext{
Ms Del Amo Castrillo, Mr Lacombe, and Mr Bore are affiliated with the Intensive Care Unit at Hôpital Raymond Poincaré, AP-HP, Garches, France. Ms Vaugier and Dr Orlikowski are affiliated with Hôpital Raymond Poincaré, INSERM CIC 1429, Garches, France. Ms Falaize and Drs Prigent and Lofaso are affiliated with Service de Physiologie-Explorations Fonctionnelles, Hôpital Raymond Poincaré, AP-HP, Garches, France.
}

The authors disclose a relationship with ResMed France.

Correspondence: Frédéric Lofaso MD PhD, Services de Physiologie et Explorations Fonctionnelles, Hôpital Raymond Poincaré, AP-HP, 92380 Garches, France. E-mail: f.lofaso@rpc.aphp.fr.

DOI: $10.4187 /$ respcare. 06259 ical ventilation. ${ }^{4,5}$ When $\mathrm{CPF}$ is $\leq 270 \mathrm{~L} / \mathrm{min}$ in a medically stable patient, cough assistance is recommended as a means of preventing pneumonia, atelectasis, and respiratory failure. ${ }^{6}$ Cough efficiency can be increased by providing assistance during inspiration or expiration or both. ${ }^{7}$

Inspiratory cough-assistance techniques increase the volume inspired just before the cough. Glossopharyngeal breathing is a positive-pressure breathing technique in which the glottis projects air into the lungs and then acts as a valve, thus adding to the inspired volume. This technique, first described by Dail during a poliomyelitis epidemic in the $1940 \mathrm{~s},{ }^{8}$ is not widely known or used today and requires normal glottis function. ${ }^{9}$ Mechanical insufflation such as intermittent positivepressure breathing can be used, ${ }^{10-13}$ but this requires a cumbersome and expensive device.

Breath-stacking is another means of increasing inspiratory capacity, in which the patient takes 2 or more consecutive insufflations without exhaling. Breath-stacking can be performed using a home ventilator. ${ }^{14}$ Thus, no additional device is required, and the subject can use breath- 


\section{Comparison of Ventilator-Delivered Cough Augmentation}

stacking as needed. The glottis must be competent, and ventilation must be delivered via a volumetric mode. Another limitation is that the total insufflated volume is difficult to adjust based on tolerance. ${ }^{15}$

For patients who are not yet receiving home ventilation

See the Related Editorial on Page 355

or who do not use a volumetric mode, breath-stacking can be achieved using a manual resuscitation bag. In addition, impaired glottis function can be substituted by a one-way valve placed at the outlet port of the manual resuscitation bag to prevent exhalation between successive insufflations. ${ }^{16}$ In a recent study of subjects with Duchenne muscular dystrophy, breath-stacking produced similar CPF values when achieved with a volume-cycled ventilator or with a manual resuscitator. ${ }^{17}$ Thus, cough assistance using a resuscitation bag is a simple and inexpensive cough-augmentation technique that may be useful for preventing and managing complications in ventilated patients. However, this technique requires the intervention of a skilled caregiver.

Recently, home ventilator manufacturers have sought to improve their devices by adding inspiratory barometric or volumetric modes designed to increase inspiratory capacity and, therefore, cough performance. The volumetric cough mode (VCM) can be controlled by the patient alone and provides cough augmentation with no additional device, thereby limiting costs. Other advantages of VCM include greater accuracy in adjusting the inspired volume to the highest tolerated value and potential efficiency in patients with weak bulbar muscles.

In this study, our objective was to compare VCM to breath-stacking during volumetric mechanical ventilation in terms of tolerance and cough parameter improvements in subjects with neuromuscular disease who used a volumetric mode of noninvasive ventilation (NIV) at home and required mechanical cough assistance.

\section{Methods}

This study was approved by the French Ethics Committee (Comité de Protection des Personnes) of Saint-Germain-en-Laye, France, on September 3, 2015 (NCPP 15031) and registered on ClinicalTrials.gov as NCT 02847299. Subjects gave written informed consent before study inclusion.

\section{Subjects}

The study was performed between March 2016 and June 2017 at the home ventilation unit of the medical ICU of the Raymond Poincaré Teaching Hospital, Garches, France. We used a randomized, open, single-center, cross-

\section{QUICK LOOK}

\section{Current knowledge}

Cough impairment is a major contributor to respiratory failure in patients on home ventilation due to neuromuscular disease. Mechanical cough-assistance devices are cumbersome and costly, and their use requires the patient to be disconnected from the ventilator. When stacking ventilator breaths, the total insufflated volume may prove difficult to adjust to patient tolerance.

\section{What this paper contributes to our knowledge}

Volumetric cough mode in which intermittent deep insufflations equal to a set percentage of the baseline tidal volume are programmed on a ventilator allowing a 500\% increase in tidal volume produced higher cough peak flows compared to ventilator breath stacking in the majority of subjects with neuromuscular disease requiring noninvasive ventilation at home. Cough peak flow was generally higher with the method producing the greatest insufflated volume. Both methods should be tested to determine which performs best in an individual subject.

over design to compare 2 inspiratory cough-assistance techniques, VCM and breath-stacking. To obtain $80 \%$ power for detecting a difference of $100 \mathrm{~L} / \mathrm{min}$, with a standard deviation of $70 \mathrm{~L} / \mathrm{min}$, a within-subject correlation of 0.5 , and the alpha risk set at 5\%, 20 subjects were required. We recruited 20 subjects with neuromuscular disease during their annual follow-up visits at our post-intensive care unit, which routinely included subject education about coughassistance techniques.

Inclusion criteria were documented neuromuscular disease, home NIV with a volumetric mode, no previous experience with cough-assistance techniques, age $>18 \mathrm{y}$, hemodynamic stability, absence of acute bronchial congestion (ie, respiratory tract infection) in the past month, and $\mathrm{CPF}<270 \mathrm{~L} / \mathrm{min}$ as recommended, ${ }^{6}$ or maximum expiratory pressure $<+45 \mathrm{~cm} \mathrm{H}_{2} \mathrm{O} .{ }^{18}$ Exclusion criteria were concomitant lung disease, respiratory infection on the day of the assessment, and a tracheostomy.

At each visit, the following were recorded routinely: vital capacity, unassisted CPF, maximum expiratory pressure, and maximum inspiratory pressure. ${ }^{19}$ Slow vital capacity and CPF were measured with the same device and by the same technician in all subjects.

\section{Cough-Assistance Methods}

Breath-stacking was achieved by instructing the subjects to perform consecutive inspiratory hold insufflations 


\section{Comparison of Ventilator-Delivered Cough Augmentation}

until the lungs felt fully expanded, producing a stretching sensation across the front of the chest, or until the insufflation pressure plateau was $50 \mathrm{~cm} \mathrm{H}_{2} \mathrm{O}$. The first exhalation after this augmented insufflation was used to cough.

VCM intermittently inflated the lungs with a volume greater than the baseline tidal volume $\left(\mathrm{V}_{\mathrm{T}}\right)$. This hyperinsufflation cycle was automatically repeated after $30 \mathrm{~s}$ of usual cycles. An audio signal sounded just before the deeper breath to alert the subject. This intermittent deep breath began at $110 \%$ of the baseline $\mathrm{V}_{\mathrm{T}}$ and was volitionally increased by $10 \%$ increments until the insufflated volume reached the highest tolerated value or $500 \%$ of baseline $\mathrm{V}_{\mathrm{T}}$, or until the maximum pressure reached $50 \mathrm{~cm} \mathrm{H}_{2} \mathrm{O}$.

\section{Testing Protocol}

On the day before the test day, the subjects were familiarized with the ventilator equipped with VCM (Astral 150, Resmed, Saint-Priest, France) and with the face mask (Laerdal Medical, Limonest, France). The ventilator, commercially available in Europe, was set to deliver noninvasive volume continuous mandatory ventilation modified to allow a $500 \%$ increase in $\mathrm{V}_{\mathrm{T}}$ and was used in volumetric mode for both VCM and breath-stacking. The subjects received training in both breath-stacking and $\mathrm{VCM}$. $\mathrm{V}_{\mathrm{T}}$ and other settings were those habitually used by the subject. The number of consecutive insufflations required to optimize the breath-stacking technique was determined for each subject during the training session. Instructions were tailored to each participant.

On the test day, each subject performed both techniques in random order. All measurements were performed with the subject seated in the usual wheelchair. One physiotherapist and one technician carried out the tests, preventing leakage and performing the measurements, respectively. Great care was taken to avoid leaks around the face mask during each of the tests. The tests were performed using the settings determined during the training sessions. During coughing, the subject received strong verbal encouragement from the physiotherapist.

\section{Outcomes and Measurements}

As previously suggested, ${ }^{20}$ we chose CPF as the primary outcome measure. The secondary outcome measures were inspiratory capacity and subjective subject ratings of breathing comfort and cough effectiveness.

During coughing, flow was measured using a pneumotachograph (Fleisch\#4, Lausanne, Switzerland). Flow increases were linear at $>600 \mathrm{~L} / \mathrm{min}$ and, consequently, the volume measured during calibration with a syringe was not influenced by flows varying between $30 \mathrm{~L} / \mathrm{min}$ and $600 \mathrm{~L} / \mathrm{min}$. The flow signal was sampled at $1,000 \mathrm{~Hz}$ and recorded using an analogic-numeric system (MP100,
Biopac System, Goleta, California) and its software (Acknowledge). Throughout the tests, oxygen saturation and heart rate were monitored using a pulse oximeter.

Inspiratory capacity was calculated as $\mathrm{V}_{\mathrm{T}}$ delivered by the ventilator multiplied by the number of stacked breaths during breath-stacking and as the delivered volume during VCM. CPF was measured during coughing after the subject was disconnected from the ventilator at the end of the augmented insufflation, to avoid resistance. Subjects could rest between each cough, and total subject participation did not exceed $1 \mathrm{~h}$. In addition, care was taken to use the circuits recommended by the manufacturer. To avoid altering device performance, when the measurement circuitry was added between the subject and device, the device circuit length was decreased commensurately to ensure that resistance remained unchanged.

Each test was repeated at least 3 times..$^{21}$ The highest $\mathrm{CPF}$ value was selected if the difference did not exceed $10 \%$ of the other 2 values. At the end of each condition, breathing comfort was evaluated by the subject using a visual analog scale ${ }^{22}$ ranging from 0 (I breathe very badly) to 10 (I breathe very well). Cough effectiveness as perceived by the subject was also rated on a 10-point visual analog scale (from 0 , indicating a completely inefficient cough, to 10 , indicating a fully effective cough).

\section{Statistical Analysis}

Quantitative variables were described as median and interquartile range. To compare VCM and breath-stacking, we used the nonparametric Friedman test followed by post hoc pairwise comparisons with the Wilcoxon paired test and the Holm correction. When necessary, linear regression was used to evaluate the degree to which 2 variables were related. The percentage difference between values with VCM and breath-stacking was computed as the difference between the 2 values divided by the mean of the 2 values. $P$ values $\leq .05$ were considered significant. Statistical analyses were conducted using R 3.2.3 statistical software.

\section{Results}

Table 1 lists the main characteristics of the 20 consecutive subjects included during the study period. None of the subjects had used hyperinflation techniques in the past $5 \mathrm{y}$.

Table 2 reports the insufflation characteristics $\left(\mathrm{V}_{\mathrm{T}}\right.$, number of breaths stacked during breath-stacking, percentage of $\mathrm{V}_{\mathrm{T}}$ during VCM) and inspiratory capacity with breathstacking and VCM in each subject. Of the 20 subjects, 3 were unable to stack at least 2 insufflations during breathstacking, despite normal bulbar function; of the other 17 subjects, 12 stacked 2 cycles and 5 stacked $\geq 3$ cycles. 


\section{Comparison of Ventilator-Delivered Cough Augmentation}

Table 1. Subject Characteristics

\begin{tabular}{|c|c|c|c|c|c|c|c|c|}
\hline \# & Sex & Age, y & Diagnosis & $\begin{array}{l}\text { Mechanical } \\
\text { Ventilation } \\
\text { Duration, h } \\
\end{array}$ & $\begin{array}{c}\text { Vital } \\
\text { Capacity } \\
\text { (seated), \% } \\
\end{array}$ & $\begin{array}{c}\text { Maximum } \\
\text { Inspiratory } \\
\text { Pressure, } \mathrm{cm} \mathrm{H}_{2} \mathrm{O}\end{array}$ & $\begin{array}{c}\text { Maximum } \\
\text { Expiratory } \\
\text { Pressure, } \mathrm{cm} \mathrm{H}_{2} \mathrm{O}\end{array}$ & $\begin{array}{l}\text { Cough } \\
\text { Peak Flow, } \\
\text { L/min }\end{array}$ \\
\hline 1 & Male & 23 & DMD & 10 & 14 & 11 & 11 & 158 \\
\hline 2 & Male & 29 & SA & 8 & 28 & 29 & 32 & 191 \\
\hline 3 & Male & 29 & Ulrich & 24 & 14 & 20 & 22 & 221 \\
\hline 4 & Male & 39 & Ac.Malt. & 8 & 15 & 19 & 10 & 69 \\
\hline 5 & Female & 31 & DMD & 8 & 41 & 25 & 23 & 215 \\
\hline 6 & Male & 22 & DMD & 9 & 11 & 16 & 12 & 154 \\
\hline 7 & Male & 34 & SA & 8 & 28 & 32 & 20 & 210 \\
\hline 8 & Female & 26 & DMD & 8 & 16 & 15 & 22 & 168 \\
\hline 9 & Male & 56 & VM & 8 & 26 & 24 & 70 & 163 \\
\hline 10 & Male & 71 & Polio & 11 & 48 & 30 & 64 & 205 \\
\hline 11 & Female & 25 & DMD & 10 & 29 & 14 & 17 & 209 \\
\hline 12 & Male & 26 & DMD & 8 & 16 & 37 & 18 & 272 \\
\hline 13 & Male & 21 & DMD & 10 & 11 & 18 & 09 & 107 \\
\hline 14 & Female & 31 & SA & 8 & 26 & 32 & 21 & 185 \\
\hline 15 & Female & 51 & G.glyc. & ND & 6 & 03 & 04 & 56 \\
\hline 16 & Female & 33 & SA & 8 & 12 & 22 & 14 & 98 \\
\hline 17 & Male & 54 & SA & ND & 34 & 59 & 27 & 208 \\
\hline 18 & Male & 37 & $\mathrm{BD}$ & 8 & 30 & 14 & 35 & 262 \\
\hline 19 & Male & 57 & SA & 12 & 7 & 08 & 07 & 56 \\
\hline 20 & Male & 50 & G.glyc. & 8 & 18 & 14 & 17 & 141 \\
\hline Median/IQR & & & & & $17 / 14$ & $21 / 15$ & $21 / 10$ & $176 / 68$ \\
\hline $\begin{array}{l}\text { DMD = Duchenn } \\
\text { SA = spinal amy } \\
\text { Ulrich = Ulrich s } \\
\text { Ac.Malt. = acid } \\
\text { VM = vacuolar } \\
\text { Polio = poliomy } \\
\text { G.glyc. = gamma } \\
\text { ND = not determ } \\
\text { BD }=\text { Becker mu }\end{array}$ & $\begin{array}{l}\text { sscular dystro } \\
\text { hy } \\
\text { ome } \\
\text { se deficiency } \\
\text { thy } \\
\text { oglycanopath } \\
\text { r dystrophy }\end{array}$ & & & & & & & \\
\hline
\end{tabular}

During VCM, all 20 subjects were able to take in a volume greater than the $\mathrm{V}_{\mathrm{T}}$, and 16 subjects took in at least twice the $\mathrm{V}_{\mathrm{T}}$. Finally, inspiratory capacity at the end of the augmented insufflation was not significantly different between breath-stacking and VCM.

Figure 1 shows the individual $\mathrm{CPF}$ values. CPF was always lower without than with mechanical cough assistance. In 16 subjects, CPF was higher with VCM than with breath-stacking. CPF values differed significantly across the 3 conditions (baseline, VCM, and breath-stacking: $P<.001)$. In the pairwise comparisons, CPF with VCM was higher than at baseline and with breath-stacking $(P<.001$ and $P<.001$, respectively), and $\mathrm{CPF}$ with breath-stacking was higher than at baseline $(P=.004)$.

Figure 2 shows that the percentage CPF difference between VCM and breath-stacking correlated with the percentage inspiratory capacity difference between VCM and breath-stacking during the inspiratory phase of the coughassistance maneuver $(\mathrm{r}=0.82$ and $P=.001)$.

Comfort and subjective cough effectiveness as rated by the subjects were similar with the 2 techniques (Table 3 ).

\section{Discussion}

We report the first comparison of breath-stacking during volumetric NIV versus preprogramed adjusted hyperinsufflation delivered by the same ventilator (VCM) as cough-assistance methods in subjects with neuromuscular disease. Both methods improved CPF. Mean CPF was higher with VCM than with breath-stacking. However, the analysis of individual results showed that breath-stacking did not improve CPF in all subjects and that VCM did not always produce higher CPF values than breath-stacking. Therefore, both methods should be evaluated to determine which is best for each patient.

$\mathrm{CPF}$ values $>270 \mathrm{~L} / \mathrm{min}$ were achieved in only 3 subjects with breath-stacking and in 7 subjects with VCM. Among the 8 subjects whose baseline $\mathrm{CPF}$ was $<180$ L/min, 6 with breath-stacking and 3 with VCM were unable to increase their $\mathrm{CPF}$ above this value. Neither technique is among the most sophisticated available to date, and both act only on the inspiratory phase of the cough. 


\section{Comparison of Ventilator-Delivered Cough Augmentation}

Table 2. Characteristics of the Inspiratory Phase of Cough Maneuvers With the Two Techniques

\begin{tabular}{|c|c|c|c|c|c|c|}
\hline \# & $\mathrm{V}_{\mathrm{T}}, \mathrm{L}$ & $\begin{array}{c}\mathrm{V}_{\mathrm{T}} / \mathrm{IBW} \\
\mathrm{mL} / \mathrm{kg}\end{array}$ & $\begin{array}{l}\text { Number of } \\
\text { Breaths } \\
\text { Stacked, no. }\end{array}$ & $\begin{array}{l}\text { IC Delivered } \\
\text { During Breath } \\
\text { Stacking, L }\end{array}$ & $\begin{array}{l}\% \text { of } \mathrm{V}_{\mathrm{T}} \\
\text { during } \\
\mathrm{VCM}\end{array}$ & $\begin{array}{l}\text { IC Delivered } \\
\text { During VCM, L }\end{array}$ \\
\hline 1 & 450 & 7 & 2 & 900 & 400 & 1,800 \\
\hline 2 & 580 & 10 & 3 & 1,740 & 400 & 2,320 \\
\hline 3 & 670 & 9 & 2 & 1,340 & 180 & 1,206 \\
\hline 4 & 810 & 17 & 1 & 810 & 120 & 972 \\
\hline 5 & 350 & 6 & 7 & 2,450 & 500 & 1,750 \\
\hline 6 & 450 & 7 & 4 & 1,800 & 400 & 1,800 \\
\hline 7 & 500 & 7 & 5 & 2,500 & 330 & 1,650 \\
\hline 8 & 550 & 8 & 2 & 1,100 & 200 & 1,100 \\
\hline 9 & 650 & 9 & 2 & 1,300 & 380 & 2,470 \\
\hline 10 & 450 & 8 & 1 & 450 & 380 & 1,710 \\
\hline 11 & 700 & 13 & 2 & 1,400 & 180 & 1,260 \\
\hline 12 & 700 & 11 & 2 & 1,400 & 230 & 1,610 \\
\hline 13 & 550 & 12 & 2 & 1,100 & 230 & 1,265 \\
\hline 14 & 480 & 10 & 1 & 480 & 300 & 1,440 \\
\hline 15 & 970 & 18 & 2 & 1,940 & 220 & 2,134 \\
\hline 16 & 520 & 9 & 2 & 1,040 & 190 & 988 \\
\hline 17 & 800 & 13 & 2 & 1,600 & 260 & 2,080 \\
\hline 18 & 650 & 11 & 2 & 1,300 & 240 & 1,560 \\
\hline 19 & 550 & 11 & 2 & 1,100 & 180 & 990 \\
\hline 20 & 760 & 12 & 4 & 3,040 & 320 & 2,432 \\
\hline Median & 565 & 10 & 2 & 1,320 & 250 & 1,630 \\
\hline Q1 & 495 & 8 & 2 & 1,085 & 198 & 1,247 \\
\hline Q3 & 700 & 12 & 3 & 1,755 & 380 & 1,870 \\
\hline \multicolumn{7}{|c|}{$\begin{array}{l}\text { Wilcoxon test, } P=.12 . \\
\mathrm{V}_{\mathrm{T}}=\text { tidal volume }(\text { delivered by the ventilator) } \\
\text { IBW = ideal body weight } \\
\text { IC = inspiratory capacity } \\
\mathrm{VCM}=\text { volumetric cough mode } \\
\mathrm{Q} 1=\text { first quartile, } \mathrm{Q} 3=\text { third quartile }\end{array}$} \\
\hline
\end{tabular}

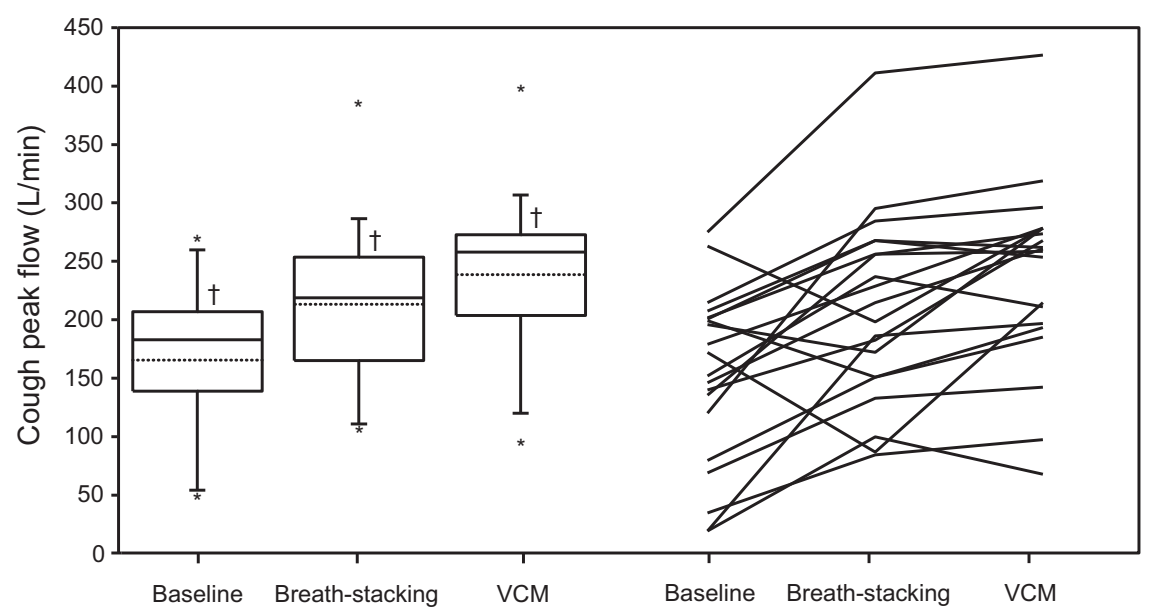

Fig. 1. Cough peak flow at baseline and with the 2 cough-assistance techniques: breath stacking during volumetric mechanical ventilation and volumetric cough mode (VCM). Box plots indicate the 25th percentile, the median, and the 75th percentile. Whiskers show the 5th and 95th percentiles. Dotted lines indicate the means. ${ }^{*}=$ outliers; $\dagger=$ different from the other conditions, Wilcoxon paired test. Friedman test: $P<.001$. 


\section{Comparison of Ventilator-Delivered Cough Augmentation}

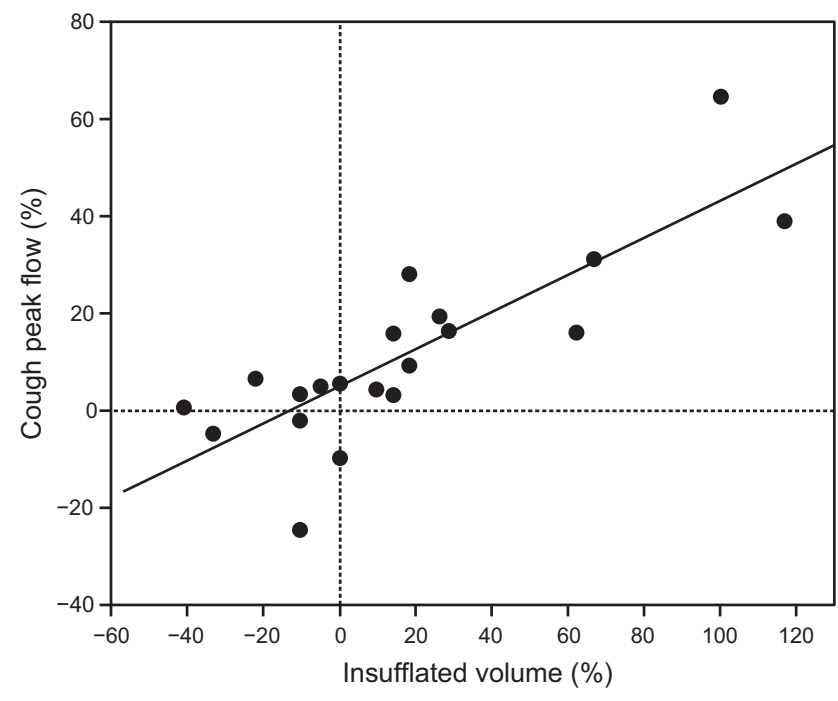

Fig. 2. Relationship between the percentage cough peak flow (difference between volumetric cough mode (VCM) and breath stacking and the percentage inspiratory capacity (difference between VCM and breath stacking divided by the mean). These 2 variables correlated significantly with each other (linear regression $r=0.82$, $P<.001)$.

Table 3. Subjective Evaluations of Breathing Comfort and Cough Effectiveness Sensation

\begin{tabular}{|c|c|c|c|c|}
\hline \multirow{2}{*}{$\#$} & \multicolumn{2}{|c|}{ Comfort With } & \multicolumn{2}{|c|}{ Cough Effectiveness With } \\
\hline & Breath Stacking & VCM & Breath Stacking & $\mathrm{VCM}$ \\
\hline 1 & 3.2 & 6.1 & 5.8 & 5.4 \\
\hline 2 & 7.6 & 5.6 & 5.1 & 7.0 \\
\hline 3 & 6.4 & 5.0 & 7.0 & 6.5 \\
\hline 4 & 9.0 & 5.5 & 5.0 & 4.9 \\
\hline 5 & 8.7 & 8.8 & 7.6 & 9.3 \\
\hline 6 & 9.7 & 9.5 & 7.8 & 8.7 \\
\hline 7 & 9.6 & 9.8 & 9.4 & 9.0 \\
\hline 8 & 7.4 & 7.0 & 7.0 & 8.1 \\
\hline 9 & 5.9 & 9.7 & 7.1 & 9.3 \\
\hline 10 & 2.1 & 3.9 & 2.0 & 4.6 \\
\hline 11 & 3.8 & 4.9 & 5.5 & 4.7 \\
\hline 12 & 6.6 & 6.5 & 7.5 & 6.0 \\
\hline 13 & 6.8 & 3.8 & 4.8 & 4.0 \\
\hline 14 & 1.8 & 6.4 & 5.2 & 6.1 \\
\hline 15 & 4.0 & 9.3 & 7.2 & 8.5 \\
\hline 16 & 3.7 & 4.8 & 4.8 & 4.6 \\
\hline 17 & 6.7 & 6.9 & 5.5 & 4.9 \\
\hline 18 & 4.9 & 6.9 & 3.6 & 4.0 \\
\hline 19 & 7.4 & 5.3 & 6.6 & 5.7 \\
\hline 20 & 4.9 & 7.2 & 6.7 & 7.9 \\
\hline Median & 6.5 & 6.4 & 6.2 & 6.0 \\
\hline Q1 & 3.9 & 5.2 & 5.1 & 4.85 \\
\hline Q3 & 7.4 & 7.6 & 7.1 & 8.2 \\
\hline$P$ & .31 & & .17 & \\
\hline \multicolumn{5}{|c|}{$\begin{array}{l}\text { Subjects evaluated comfort and cough effectiveness on a } 0-10 \text { visual analog scale. } \\
\text { VCM }=\text { volumetric cough mode } \\
\mathrm{O} 1=\text { first guartile. } \mathrm{O} 3=\text { third guartile }\end{array}$} \\
\hline
\end{tabular}

However, breath-stacking and VCM are simple and inexpensive because they require no additional device for subjects on home NIV. In France, a cough-assistance device costs the health insurance system about $\$ 925$ per year, in addition to the cost of the ventilator. This additional cost is eliminated by using breath-stacking or VCM. Another advantage of breath-stacking and VCM that is particularly valuable when ventilatory assistance is required during the day is that the patient does not need to be disconnected from the ventilator for the cough maneuvers.

The individual analysis of our results (Fig. 2) showed that the cough-assistance method yielding the highest CPF values also produced the highest inspiratory capacity values in 17 of the 20 subjects. This information may be useful to clinicians. CPF measurement requires that patients be disconnected from the ventilator and connected to a pneumotachograph via a face mask. Thus, $\mathrm{CPF}$ is not easily measured by a clinician working alone. In contrast, inspiratory capacity during breath-stacking or a VCM inspiration is displayed on the ventilator screen.

Although we took great care to avoid leakage during the insufflations, inspiratory capacity may have been overestimated in some cases. Overestimation of inspiratory capacity may be more likely to occur during breath-stacking if the glottis does not close fully or permanently between inspirations. Such leakage through the glottis may explain the higher CPF with VCM in 3 subjects who had higher inspiratory capacity values with breath-stacking than with VCM. Nevertheless, the differences were small in these 3 subjects.

We hypothesized that VCM might be better tolerated than breath-stacking due to better volume adjustment and to the continuous hyperinsufflation with no need to refrain from exhaling between 2 insufflations. Theoretically, VCM should perform better in patients with bulbar dysfunction who cannot achieve full closure of the glottis. However, the 3 subjects who were unable to stack at least 2 cycles with breath-stacking in our study had normal bulbar function. Therefore, this point needs to be specifically evaluated in subjects with neuromuscular disease.

A limitation to the general applicability of our findings is that we used a modified ventilator that allowed a 500\% increase in $\mathrm{V}_{\mathrm{T}}$. Commercially available home ventilators capable of delivering NIV do not offer such large $V_{T}$ increases. For instance, the Astral 150 usually provides a maximum $\mathrm{V}_{\mathrm{T}}$ increase of $250 \%$, and the boost function of the Monnal T50 (Air Liquide Medical Systems, Antony, France) increases $V_{T}$ by $150 \%$. Of our 20 subjects, 10 achieved their best results with a $\mathrm{V}_{\mathrm{T}}$ increase $>250 \%$, which was well tolerated. Consequently, current home ventilators would not seem to provide optimal cough enhancement with their usual settings. This should be an incentive for manufacturers to offer additional ventilator 


\section{Comparison of Ventilator-Delivered Cough Augmentation}

settings to provide the most efficient support to subjects with cough impairment.

Tolerance was similar with both methods in our population, and the technique providing the best results differed across subjects. Therefore, patients with neuromuscular diseases should be evaluated on a case-by-case basis to determine which cough-assist technique is most beneficial. The comparison of the insufflated volume with each technique, which is provided by the ventilator, can help the patient and clinician to choose the most efficient technique.

\section{REFERENCES}

1. Ambrosino N, Carpene N, Gherardi M. Chronic respiratory care for neuromuscular diseases in adults. Eur Respir J 2009;34(2):444-451.

2. Suarez AA, Pessolano FA, Monteiro SG, Ferreyra G, Capria ME, Mesa L, et al. Peak flow and peak cough flow in the evaluation of expiratory muscle weakness and bulbar impairment in patients with neuromuscular disease. Am J Phys Med Rehabil 2002;81(7):506511.

3. Boitano LJ. Management of airway clearance in neuromuscular disease. Respir Care 2006;51(8):913-922.

4. Bach JR, Saporito LR. Criteria for extubation and tracheostomy tube removal for patients with ventilatory failure. A different approach to weaning. Chest 1996;110(6):1566-1571.

5. Goncalves MR, Honrado T, Winck JC, Paiva JA. Effects of mechanical insufflation-exsufflation in preventing respiratory failure after extubation: a randomized controlled trial. Critical care 2012;16(2): R48.

6. Bott J, Blumenthal S, Buxton M, Ellum S, Falconer C, Garrod R, et al. Guidelines for the physiotherapy management of the adult, medical, spontaneously breathing patient. Thorax 2009;64(Suppl 1): i1-i51.

7. Bach JR. Mechanical insufflation-exsufflation. Comparison of peak expiratory flows with manually assisted and unassisted coughing techniques. Chest 1993;104(5):1553-1562.
8. Dail CW. "Glossopharyngeal breathing" by paralyzed patients; a preliminary report. Calif Med 1951;75(3):217-218.

9. Pryor JA. Physiotherapy for airway clearance in adults. Eur Respir J 1999;14(6):1418-1424

10. AARC Clinical Practice Guideline. Intermittent positive pressure breathing. Respir Care 1993;38(11):1189-1195.

11. Welch MA Jr, Shapiro BJ, Mercurio P, Wagner W, Hirayama G. Methods of intermittent positive pressure breathing. Chest 1980; 78(3):463-467.

12. Trebbia G, Lacombe M, Fermanian C, Falaize L, Lejaille M, Louis A, et al. Cough determinants in patients with neuromuscular disease. Respir Physiol Neurobiol 2005;146(2-3):291-300.

13. Dohna-Schwake C, Ragette R, Teschler H, Voit T, Mellies U. IPPBassisted coughing in neuromuscular disorders. Pediatr Pulmonol 2006; 41(6):551-557.

14. Kang SW, Bach JR. Maximum insufflation capacity. Chest 2000; 118(1):61-65

15. Bach JR, Mahajan K, Lipa B, Saporito L, Goncalves M, Komaroff E. Lung insufflation capacity in neuromuscular disease. Am J Phys Med Rehabil 2008;87(9):720-725.

16. Choi WA, Park JH, Kim DH, Kang SW. Cough assistance device for patients with glottis dysfunction and/or tracheostomy. J Rehabil Med 2012;44(4):351-354.

17. Toussaint M, Pernet K, Steens M, Haan J, Sheers N. Cough augmentation in subjects with duchenne muscular dystrophy: comparison of air stacking via a resuscitator bag versus mechanical ventilation. Respir Care 2016;61(1):61-67.

18. Szeinberg A, Tabachnik E, Rashed N, McLaughlin FJ, England S, Bryan CA, et al. Cough capacity in patients with muscular dystrophy. Chest 1988;94(6):1232-1235.

19. Standardized lung function testing. Official statement of the European Respiratory Society. Eur Respir J 1993;16(Suppl):1-100.

20. Morrow B, Zampoli M, van Aswegen H, Argent A. Mechanical insufflation-exsufflation for people with neuromuscular disorders. Cochrane Database Syst Rev 2013;12:CD010044.

21. Miller MR, Hankinson J, Brusasco V, Burgos F, Casaburi R, Coates A, et al. Standardisation of spirometry. Eur Respir J 2005;26(2):319338.

22. Aitken RC. Measurement of feelings using visual analogue scales. Proc R Soc Med 1969;62(10):989-993.

This article is approved for Continuing Respiratory Care Education credit. For information and to obtain your CRCE

(free to AARC members) visit www.rcjournal.com

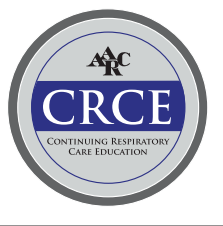

